\title{
Structural and optical properties o plasma-deposited a-C:H:Si:O:N films ${ }^{\mathrm{a}}$
}

\author{
Juliana Feletto Silveira Costa Lopes ${ }^{1}$ (D), Jean Tardelli ${ }^{1}$ (D), Elidiane Cipriano Rangel ${ }^{1}$ (D) \\ and Steven Frederick Durrant ${ }^{1 *}$ (1D
}

\author{
${ }^{1}$ Laboratório de Plasmas Tecnológicos, Instituto de Ciência e Tecnologia de Sorocaba, Universidade \\ Estadual Paulista - UNESP, Sorocaba, SP, Brasil \\ *steven.durrant@unesp.br
}

\begin{abstract}
Thin a-C:H:Si:O:N films were deposited from plasmas fed hexamethyldisiloxane, oxygen and nitrogen, and characterized as a function of the partial pressure of oxygen in the feed, $\mathrm{R}_{\mathrm{ox}}$. Deposition rates varied from 10 to $27 \mathrm{~nm} \mathrm{~min}^{-1}$. Surface roughness was independent of $\mathrm{R}_{\text {ox }}$, being around $10 \mathrm{~nm}$. The films contain $\mathrm{C}=\mathrm{C}$ and $\mathrm{C}=\mathrm{O}$, and also $\mathrm{Si}-\mathrm{C}$ and $\mathrm{Si}-\mathrm{O}-\mathrm{Si}$ groups. Lower [C] and [N] but greater [O] and [Si] were measured in the films as $\mathrm{R}_{\mathrm{ox}}$ was increased. Refractive indices of $\sim 1.5$ and optical energy gaps which fell from $\sim 3.3$ to $\sim 2.3 \mathrm{eV}$ were observed with increasing $\mathrm{R}_{\text {ox }}$. The Urbach energy fell with increasing optical gap, which is characteristic of amorphous materials. Such materials have potential as transparent barrier coatings.
\end{abstract}

Keywords: plasma enhanced chemical vapor deposition; optical band gap; urbach energy.

How to cite: Lopes, J. F. S. C., Tardelli, J., Rangel, E. C., \& Durrant, S. F. (2021). Structural and optical properties of plasma-deposited a-C:H:Si:O:N films. Polímeros: Ciência e Tecnologia, 31(3), e2021035. https://doi.org/10.1590/01041428.210043.

\section{Introduction}

Thin films of a-C:H:Si:N ${ }^{[1-8]}$, a-C:H:Si:O ${ }^{[9-20]}$, and a-C:H:Si:O: $\mathrm{N}^{[21-24]}$, where a designates amorphous, have been produced by plasma deposition from diverse monomers and comonomers. For example, a-C:H:Si: $\mathrm{N}$ has been produced, among others, in plasmas fed hexamethyldisilazane and nitrogen ${ }^{[1]}$, diethylsilane and ammonia ${ }^{[3]}$, and methane, silane and nitrogen ${ }^{[5]}$. Similarly, a-C:H:Si:O has been produced from plasmas of hexamethyldisiloxane (HMDSO) ${ }^{[9]}$, trimethylmethoxysilane and argon ${ }^{[10]}$, and HMDSO and $\operatorname{argon}^{[12]}$. Films of a-C:H:Si:O:N have been deposited from plasmas fed HMDSO, acetylene and nitrogen ${ }^{[22]}$, and from tetramethlydisilazane, oxygen and nitrogen ${ }^{[23]}$. Applications of a-C:H:Si:N include electrical insulation, protective layers $^{[1]}$, and electronic passivation of n-type c-silicon ${ }^{[25]}$. Amorphous C:H:Si:O films show promise as hydrophobic and corrosion protection layers ${ }^{[13,18]}$.

In the plasma enhanced chemical vapor deposition (PECVD) of $\mathrm{HMDSO} / \mathrm{O}_{2}$ mixtures film precursors of mass 148, such as $\mathrm{Me}_{3}-\mathrm{Si}-\mathrm{O}-\mathrm{Si}=\mathrm{O}-\mathrm{Me}$, where Me represents methyl, and related $\mathrm{Si}-\mathrm{O}, \mathrm{Si}-\mathrm{OH}$ and $\mathrm{C}=\mathrm{O}$ have been detected ${ }^{[16]}$. Species present in the plasma phase include $\mathrm{H}, \mathrm{CH}$ and $\mathrm{CO}^{[26]}$. At high proportions of $\mathrm{O}_{2}$ in the feed, $\mathrm{O}, \mathrm{CO}, \mathrm{OH}$ and $\mathrm{H}$ are observed, along with $\mathrm{CO}^{+}$and $\mathrm{CO}_{2}^{+[27]}$. Another known feature of HMDSO-O $\mathrm{O}_{2}$ plasmas is the production

of $\mathrm{SiO}_{\mathrm{x}}$ powder ${ }^{[28]}$. There are few studies, however, dealing directly with a-C:H:Si:O:N films. An exception is the study of films produced from $\mathrm{HMDSO}-\mathrm{N}_{2}$ mixtures at atmospheric pressure in a dielectric barrier discharge ${ }^{[29]}$. At high values of $\left[\mathrm{N}_{2}\right] /\left(\left[\mathrm{Ar}+\mathrm{N}_{2}\right]\right)$, Si-N groups were detected in the films. Amine and silazane moieties were present.

The present study focuses on plasma-deposited a-C:H:Si:O:N produced from $\mathrm{HMDSO}$ with $\mathrm{O}_{2}$ and $\mathrm{N}_{2}$. There are few extant studies of such material. The following characterizations of the films allow a composite picture of key properties for possible applications to be mapped. Therefore, morphological, chemical, structural and compositional features, together with optical properties were obtained. Surface roughness and morphology were studied using profilometry and scanning electron microscopy (SEM) respectively. Surface contact angles were measured using goniometry. Chemical structure and composition were probed using infrared reflection-absorption spectroscopy (IRRAS) and energy dispersive X-ray spectroscopy (EDS). The refractive index, optical energy gap, and Urbach energy of the films were calculated from film thickness and ultraviolet-visible near infrared spectroscopy (UVS) data. Subsequently, this suite of properties was used to suggest possible applications.

a This paper has been partially presented at the 3rd International Conference on Materials Sciences and Nanomaterials, ICSMN 2019, Oxford University, Oxford, UK, 22nd to 24th July 2019. 


\section{Materials and Methods}

The deposition system is shown in Figure 1.

Films were deposited in a cylindrical stainless-steel chamber, containing two circular, horizontal, parallel-plate electrodes. Radiofrequency (13.56 MHz) power was fed from a supply (Tokyo Hy-Power, MB-300) at $70 \mathrm{~W}$, via a matching network used to minimize the reflected power, to the lower electrode, while the upper electrode was grounded. Pressure was monitored using a Pirani gauge (Agilent, PCG-750). The base pressure was $\sim 0.7 \mathrm{~Pa}$. Nitrogen and oxygen gases (99.95\% pure, White Martins, Brazil) were admitted to the chamber from cylinders via precision leak valves (Edwards, LV10-K). For HMDSO, vapor was introduced via a leak valve from a vial of the liquid reagent. For depositions, the chamber was evacuated continuously using a rotary vane pump (Edwards, E2M18). A HMDSO partial pressure of 8.0 Pa was maintained for all depositions. The stoichiometry of the films was altered by varying the partial pressures of oxygen and nitrogen, while maintaining a total pressure of these two gases at $8.0 \mathrm{~Pa}$. All depositions lasted $30 \mathrm{~min}$.

Substrates, placed on the lower electrode, were of glass, polished stainless steel, and quartz. The glass substrates were used for films examined by profilometry, and goniometry. Polished stainless steel substrates were used for films examined by IRRAS, SEM and EDS. Quartz substrates were employed for films examined by UVS.

Film deposition rates were calculated by dividing the film thickness, h, by the deposition time, t. Film thickness was obtained from a film deposited on a glass slide partially covered by an adhesive tape. Subsequent removal of the tape produced a well-defined film edge, which was measured using profilometry (Veeco DekTak 150). Surface roughness, $\mathrm{R}_{\mathrm{a}}$, was calculated using the arithmetic method from film surface profiles, where $\mathrm{R}_{\mathrm{a}}$ is the average of the sum of the absolute values of the deviations from the mean height ${ }^{[30]}$.

Surface morphology was examined using SEM (Jeol JSM-6010LA) and elemental analysis carried out using an EDS accessory (Dry SD Hyper (EX 94410T1L11)). Surface contact angle measurements were made with drops of distilled deionized water using a goniometer (Krüss DSA25E). Ten measurements were made on each of three drops placed at different positions on the film.

Infrared reflection absorption spectroscopy (IRRAS) was used to accumulate spectra with a Jasco FTIR-410 instrument over the wavenumber range from 400 to $4000 \mathrm{~cm}^{-1}$. Each spectrum was obtained using 128 scans at a resolution of $4 \mathrm{~cm}^{-1}$.

A Perkin Elmer Lambda 750 ultraviolet-visible near infrared spectrometer was used to collect spectra in the wavelength interval of 300 to $2500 \mathrm{~nm}$. For most of the spectra it was possible to determine the refractive index, $\mathrm{n}$, of the film using a method given by Cisneros et al. ${ }^{[31]}$. When interference maxima and minima are present in a transmittance spectrum, each extremum has an associated integer, $\mathrm{m}$, given by:

$$
m \approx \lambda_{m-1} /\left(\lambda_{m-1}-\lambda_{m}\right)
$$

Employing this relation and

$$
m=4 n h / \lambda_{m}
$$

$n$ may be calculated. The absorption coefficient, $\alpha(E)$, can also be calculated as a function of the photon energy (E). When Tauc plots exhibit a linear region, extrapolation to the $\mathrm{x}$-axis (which shows the variable E) reveals the optical energy gap ${ }^{[32]}$, which we designate as the Tauc gap.

\section{Results and Discussion}

Figure 2 shows the film deposition rate as a function of $\mathrm{R}_{\mathrm{ox}}$. Oxygen is very reactive and fragmentation of HMDSO increases rapidly as $\mathrm{R}_{\mathrm{ox}}$ is increased, roughly doubling the deposition rate for intermediate values of $\mathrm{R}_{\mathrm{ox}}$. Film deposition, however, is reduced by etching by atomic $\mathrm{O}$. Thus, for $\mathrm{R}_{\mathrm{ox}}$ of 4.0 $\mathrm{Pa}$ the deposition rate is decreased to close to its value in the absence of oxygen in the feed. For greater $\mathrm{R}_{\mathrm{ox}}$, etching exceeds film growth and no film is produced.

Groups such as $\mathrm{CH}_{\mathrm{x}}(\mathrm{x}=1$ to 3$)$ and silicon-containing molecular fragments are film precursors. As proposed by Balu et al. ${ }^{[33]}$ hydrocarbon groups may also be etched via reactions of the form:

$$
\begin{aligned}
& R+\mathrm{O} \rightarrow \mathrm{R} \bullet+\mathrm{OH} \\
& R+\mathrm{OH} \rightarrow \mathrm{R} \bullet+\mathrm{H}_{2} \mathrm{O} \\
& \mathrm{R} \bullet+\mathrm{O} \rightarrow \mathrm{RO}^{\prime}+\mathrm{CO}+\mathrm{CO}_{2}
\end{aligned}
$$

where $\mathrm{R}$ is the polymer backbone and $\mathrm{O}$ represents radical or excited oxygen produced in the plasma. The volatile species are lost to the pumping system. In addition, to such species, ions also play a role in film deposition. For example, ions such as $\mathrm{O}_{2}^{+}$may create surface active sites, remove reaction products held on the film surface, supply energy to drive surface reactions or remove material by direct reactive ion etching ${ }^{[34]}$.

Oxygen ions, such as $\mathrm{O}_{2}^{+}$may be produced in the plasma by reactions ${ }^{[34]}$ such as those given in Equations 6 to 9 .

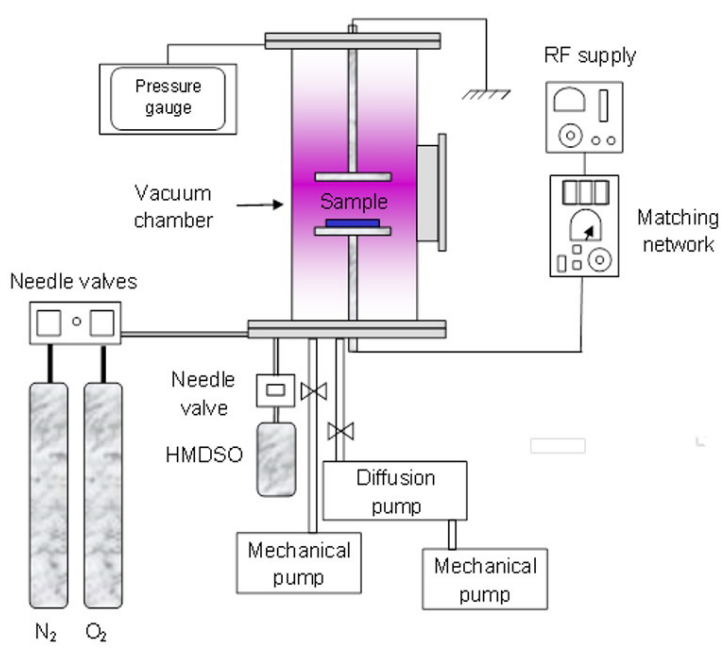

Figure 1. Schematic of the PECVD system. 


$$
\begin{aligned}
& e+\mathrm{O}_{2} \rightarrow \mathrm{O}_{2}{ }^{*}+e \\
& \rightarrow 2 \mathrm{O}+e \\
& \rightarrow \mathrm{O}^{*}+\mathrm{O}+e \\
& \rightarrow \mathrm{O}_{2}{ }^{+}+2 e
\end{aligned}
$$

Subsequently, carbon may be etched, for example, via reactions $^{[34]}$ indicated in Equations 10 and 11.

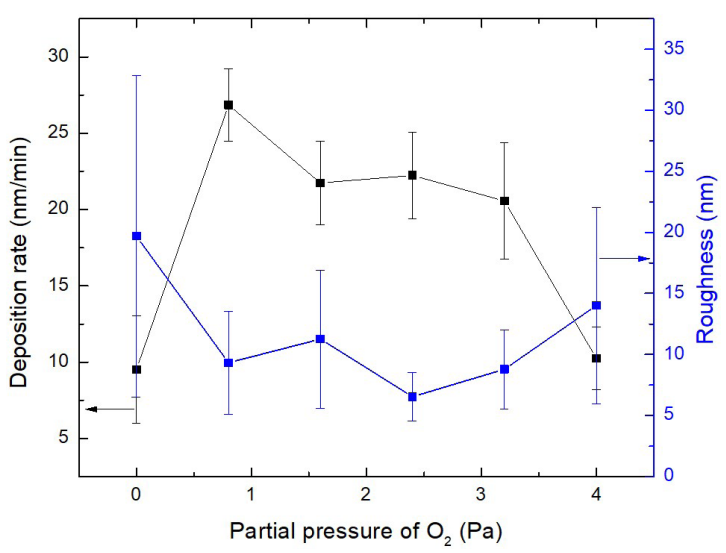

Figure 2. Deposition rate (mean and standard deviation of 6 measurements) and roughness (mean and standard deviation of 6 measurements) as a function of $\mathrm{R}_{\mathrm{ox}}$. Films were deposited on glass substrates.

$$
\begin{aligned}
& 2(n+1) \mathrm{C}+\mathrm{O}_{2}{ }^{+}+n \mathrm{O}_{2} \rightarrow 2(n+1) \mathrm{CO} \\
& 2(m+1) \mathrm{C}+\mathrm{O}_{2}{ }^{+}+\mathrm{mO}_{2} \rightarrow(m+1) \mathrm{CO}_{2}
\end{aligned}
$$

Figure 2 also shows the film surface roughness as a function of $\mathrm{R}_{\mathrm{ox}}$. While no systematic variation is observed, the absolute values are all small, $\sim 10 \mathrm{~nm}$, and the error bars of the measurements overlap. Thus, under the conditions used, etching does not significantly alter the surface roughness.

Scanning electron micrographs of the surface of the films grown at different $\mathrm{R}_{\mathrm{ox}}$ are shown in Figure 3.

A few, roughly spherical features, of diameter up to $\sim 1 \mu \mathrm{m}$ are seen in the micrographs of the films deposited at $\mathrm{R}_{\mathrm{ox}}$ of 0.8 to $2.4 \mathrm{~Pa}$. In cold plasmas containing HMDSO particles often form ${ }^{[26]}$, and when sufficiently large become negatively charged, which keeps them suspended. As the plasma is rich in hydrogen, the particles heat-up owing to surface recombination, which is exothermic. This, in turn, increases the oxidation rate of organic matter.

Water contact angle, $\theta$, is shown as a function of $R_{o x}$ in Figure 4. There is a fall in $\theta$ from $\sim 90^{\circ}$ for the film deposited without oxygen in the feed to $\sim 73^{\circ}$ for the film produced at an oxygen partial pressure of $3.2 \mathrm{~Pa}$. Increased film oxygen content may be responsible for this.

Figure 5 presents IRRAS spectra for the films deposited at different $\mathrm{R}_{\mathrm{o}}$. A peak centered at $23400 \mathrm{~cm}^{-1}$ shifts to $\sim 3600 \mathrm{~cm}^{-1}$ as $\mathrm{R}_{\text {ox }}$ increases. This absorption is attributed to hydroxyl groups and, at higher $\mathrm{R}_{\mathrm{ox}}$, specifically to $\mathrm{OH} v$ in free $\mathrm{SiOH}$. Absorptions at 2960 and $2900 \mathrm{~cm}^{-1}$ are seen in the spectra of the films deposited at low $\mathrm{R}_{\mathrm{ox}}$. These are

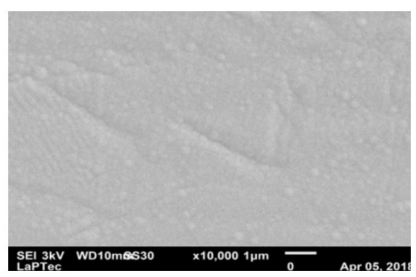

(b)

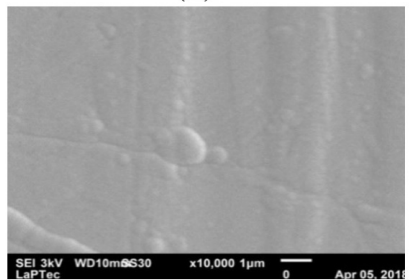

(d)

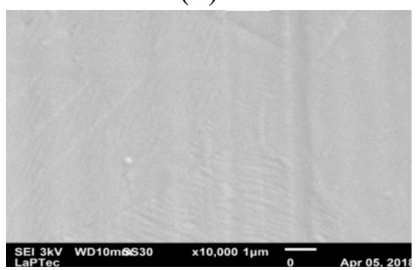

(f)

(e)

$=0 \mathrm{~Pa} ;$ (b) $\mathrm{R}_{\mathrm{ox}}=0.8 \mathrm{~Pa} ;$ (c) $\mathrm{R}_{\mathrm{ox}}=1.6 \mathrm{~Pa} ;(\mathrm{d}) \mathrm{R}_{\mathrm{ox}}$ Figure 3. Scanning electron micrographs of the surface of the films deposited at (a) $R_{o x}$
$=2.4 \mathrm{~Pa}$; (e) $R_{o x}=3.2 \mathrm{~Pa}$; (f) $R_{o x}=4.0 \mathrm{~Pa}$. Films were deposited onto glass substrates. 


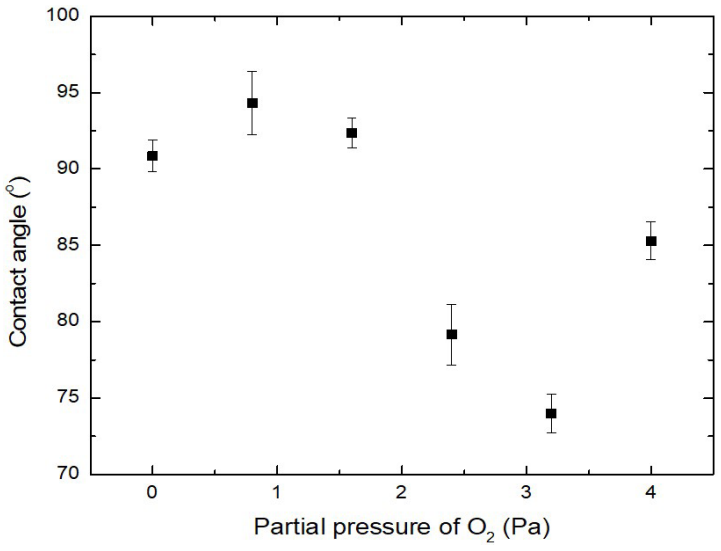

Figure 4. Water surface contact angles (mean and standard deviation of 30 measurements) as a function of $\mathrm{R}_{\mathrm{ox}}$. Films were deposited on glass substrates.

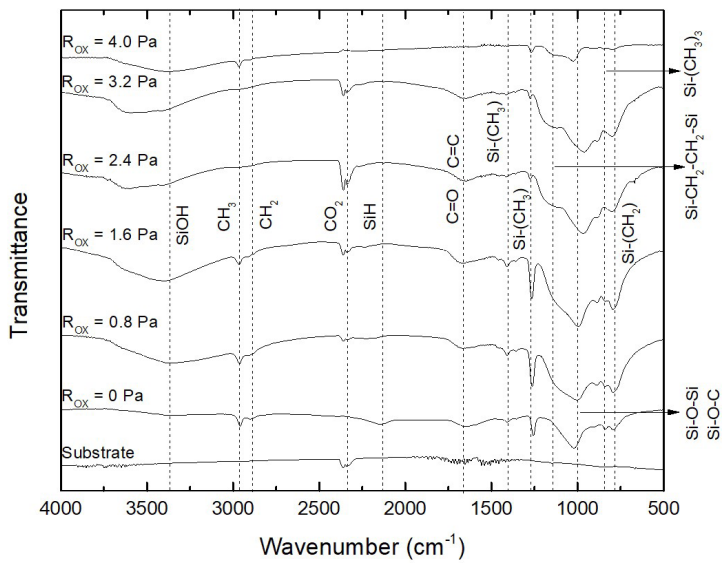

Figure 5. IRRAS spectra of films deposited at different values of $\mathrm{R}_{\mathrm{ox}}$. Film thicknesses were as follows: $\mathrm{R}_{\mathrm{ox}}=0 \mathrm{~Pa}(286 \mathrm{~nm})$; $\mathrm{R}_{\mathrm{ox}}=0.8 \mathrm{~Pa}(805 \mathrm{~nm}) ; \mathrm{R}_{\mathrm{ox}}=1.6 \mathrm{~Pa}(652 \mathrm{~nm}) ; \mathrm{R}_{\mathrm{ox}}=2.4 \mathrm{~Pa}(667 \mathrm{~nm}) ;$ $\mathrm{R}_{o x}=3.2 \mathrm{~Pa}(617 \mathrm{~nm}) ; \mathrm{R}_{\mathrm{ox}}=4.0 \mathrm{~Pa}(307 \mathrm{~nm})$. Films were deposited onto polished stainless-steel substrates.

attributed to $\mathrm{C}-\mathrm{H}$ stretching in $\mathrm{CH}_{3}$ and $\mathrm{CH}_{2}$, respectively. Each spectrum exhibits an absorption at $\sim 840 \mathrm{~cm}^{-1}$ caused by $-\mathrm{CH}_{3} \rho$ in $\mathrm{Si}\left(\mathrm{CH}_{3}\right)_{3}{ }^{[19,35,36]}$.

Although oxygen is present in the HMDSO molecule, as residual gas in the deposition chamber, and it is also known that post-deposition reactions may occur between free radicals in plasma polymers and ambient oxygen and

water $^{[37,38]}$, no significant absorptions attributable to hydroxyl groups are present in the spectrum of the film deposited at zero $\mathrm{R}_{\mathrm{ox}}$. For all non-zero $\mathrm{R}_{\mathrm{ox}}$, however, hydroxyl groups are present in the film. This suggests that the incorporation of hydroxyl groups is mainly dependent on oxygen deliberately introduced into the chamber feed.

Silicon is not bonded to hydrogen in HMDSO but an absorption at $2100 \mathrm{~cm}^{-1}$, attributed to $\mathrm{SiH}$, is present in the spectrum of the film grown at zero $\mathrm{R}_{\mathrm{ox}}$. Overlapping absorptions occur near $1000 \mathrm{~cm}^{-1}$, are attributed to $\mathrm{Si}-\mathrm{O}-\mathrm{Si}$ and Si-O-C. Ethylene and methylene groups are expected to be produced by moderate fragmentation of the HMDSO molecule. The Si-O-Si structure is also found in the monomer. No Si-O-C structures are present in the monomer. A small shoulder is apparent at $\sim 1160 \mathrm{~cm}^{-1}$ in the spectra of films grown at greater $\mathrm{R}_{\mathrm{ox}}$, and this is attributed to $\mathrm{Si}-\mathrm{CH}_{2}-\mathrm{CH}_{2}-$ $\mathrm{Si}$ and is indicative of a loss of hydrogen in relation to the HMDSO molecule. As nitrogen concentrations in the films are only a few at.\% (as discussed below in relation to the EDS data) there are no well-defined absorptions caused by nitrogen-containing groups.

A small band, whose center lies in the 1630 to $1700 \mathrm{~cm}^{-1}$ region, depending on $\mathrm{R}_{\mathrm{ox}}$, may be caused by stretching in $\mathrm{C}=\mathrm{C}$ and $\mathrm{C}=\mathrm{O}$, respectively. Neither of these structures (nor $\mathrm{SiH}$ ) is present in the monomer molecule, indicating that multiple-step reactions occur in their formation.

Figure 6 shows the relative concentration, calculated using the method of Lanford and Rand ${ }^{[39]}$, of Si-O bonded to $\mathrm{Si}$ or $\mathrm{C}$, and of $\mathrm{OH}$ as a function of $\mathrm{R}_{\mathrm{ox}}$. As $\mathrm{Si}-\mathrm{O}-\mathrm{Si}$ is the central structure of the HMDSO molecule, it is retained at high concentrations despite considerable variation in [O] and $[\mathrm{C}]$ as discussed below in relation to EDS analyses. The steep rise in $[\mathrm{OH}]$ with increasing $\mathrm{R}_{\mathrm{ox}}$ clearly indicates the strong incorporation of oxygen as a hydroxide.

As also shown in Figure 6, $\left[\mathrm{Si}(\mathrm{CH})_{3}\right]$ and $[\mathrm{CH}]$ fall with increasing $\mathrm{R}_{\mathrm{ox}}$ and rise only for $\mathrm{R}_{\mathrm{ox}}>3.2 \mathrm{~Pa}$. This reflects the loss of hydrogen and carbon with increasing $\mathrm{R}_{\mathrm{ox}}$.

Figure 7 shows the concentration (at.\%) of the elements $\mathrm{C}, \mathrm{O}, \mathrm{Si}$ and $\mathrm{N}$ as determined by EDS as a function of $\mathrm{R}_{\mathrm{ox}}$ (the hydrogen content cannot be measured and has been ignored). In the HMDSO molecule the number $\mathrm{O}, \mathrm{Si}$ and $\mathrm{C}$ atoms are, $11 \%, 22 \%$ and $67 \%$, respectively. Compared to this, $[\mathrm{O}]$ and $[\mathrm{Si}]$ increase, while $[\mathrm{C}]$ decreases, in the film deposited without oxygen in the feed.

The concentration of carbon, [C], falls with increasing $R_{o x}$, except beyond a $R_{o x}$ of $3.2 \mathrm{~Pa}$, where it rises. Both $[\mathrm{O}]$ and $[\mathrm{Si}$ ] rise with increasing $\mathrm{R}$, except beyond a $\mathrm{R}$ of $3.2 \mathrm{~Pa}$, where the concentrations of both elements fall. These decreases in $[\mathrm{O}]$ and $[\mathrm{Si}]$ at high $\mathrm{R}_{\mathrm{ox}}$ may be caused by synergistic effects between $\mathrm{O}$ and $\mathrm{O}_{2}^{+}$, producing etching and sputtering. For $\mathrm{R}_{\mathrm{ox}}$ in the interval from 0.8 to $3.2 \mathrm{~Pa}, \theta$ falls and $[\mathrm{O}]$ rises (Figure 4 and Figure 7). For $\mathrm{R}_{\text {ox }}$ greater than $3.2 \mathrm{~Pa}, \theta$ rises and $[\mathrm{O}]$ falls. Thus, greater values of $[\mathrm{O}]$ are associated with smaller contact angles. Inspection of Figure 7 also shows that $[\mathrm{N}]$ falls from $\sim 6$ at. $\%$ for zero $\mathrm{R}_{\mathrm{ox}}$ to $\sim 0$ at.\% when $\mathrm{R}_{\mathrm{ox}}$ is increased to $4.0 \mathrm{~Pa}$. This reflects the diminishing supply of nitrogen in the plasma feed as $\mathrm{R}_{\mathrm{ox}}$ is increased.

Figure 8 shows the transmittance spectra of the films grown at different $\mathrm{R}_{\mathrm{ox}}$ in the ultraviolet-visible near infrared region. Multiple interference extrema are observed for wavelengths above about $500 \mathrm{~nm}$. The inset of Figure 8 shows the refractive index of the deposited material as a function of $\mathrm{R}_{\mathrm{ox}}$. Typical values of $\mathrm{n}$ are $\sim 1.5$, lower than those found for films deposited from diethylsilane, ammonia and nitrogen, which are typically 1.7 to 1.8 , depending on the deposition temperature ${ }^{[2]}$. The films of the present study, however, differ in having low nitrogen contents. As the refractive index depends on the effective polarizability, the molar mass and the density ${ }^{[40]}$, the relative constancy of $n$ implies 


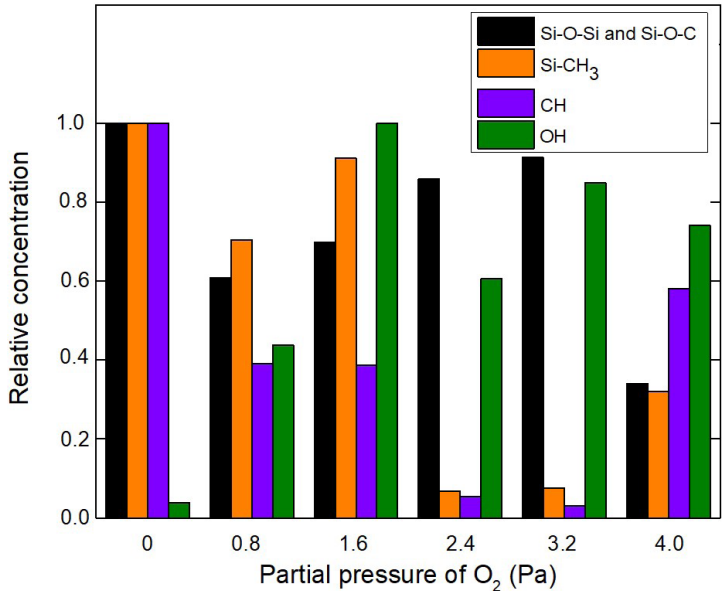

Figure 6. Relative concentration of $\mathrm{Si}-\mathrm{O}-\mathrm{Si}, \mathrm{Si}-\mathrm{O}-\mathrm{C}, \mathrm{Si}-\mathrm{CH}_{3}$, $\mathrm{CH}$, and $\mathrm{OH}$ as a function of $\mathrm{R}_{\mathrm{ox}}$. These values were calculated from the area of the relevant infrared absorption divided by the film thickness, and were normalized to the maximum obtained for each species.

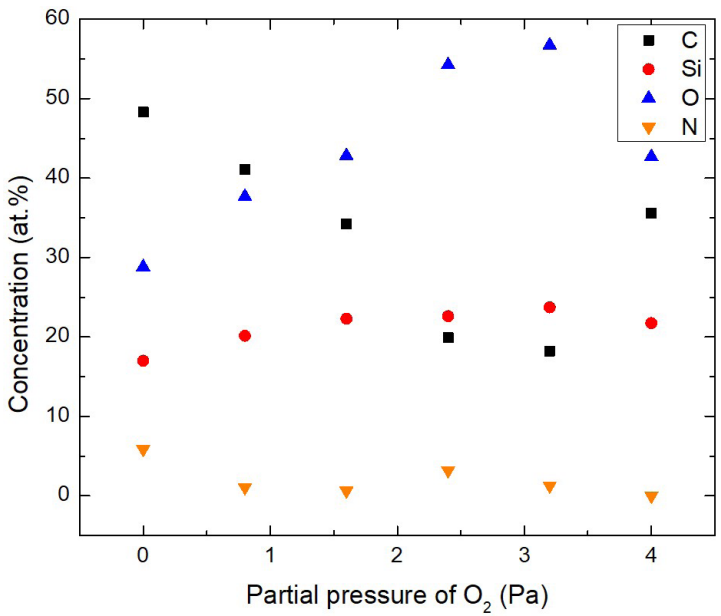

Figure 7. Atomic concentration of $\mathrm{C}, \mathrm{O}, \mathrm{Si}$ and $\mathrm{N}$ in the films determined by EDS as a function of $\mathrm{R}_{\mathrm{ox}}$.

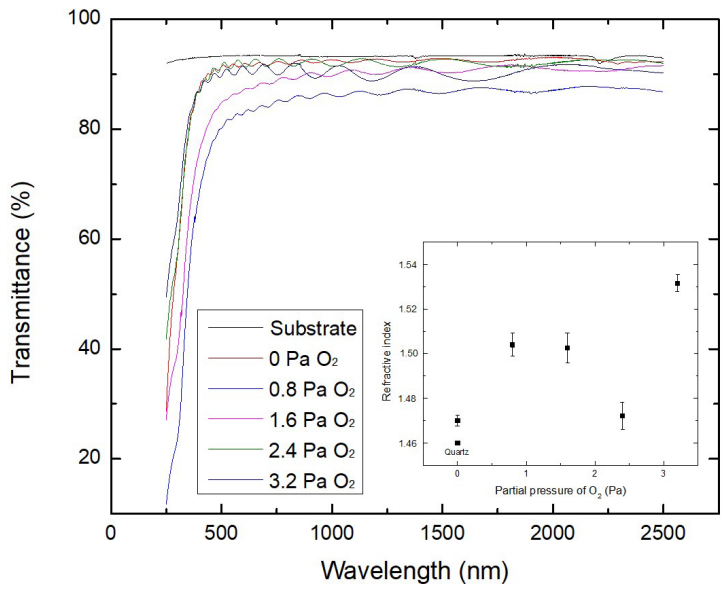

Figure 8. Transmittance spectra for films deposited at different $\mathrm{R}_{\mathrm{ox}}$. Films were deposited onto quartz substrates. Inset shows the refractive index of the deposited material as a function of $R_{o x}$. that the effects in any changes in these parameters tend to cancel out. Values of $\mathrm{n}$ close to 1.5 were also found by Mota et al. ${ }^{[19]}$ for a-C:H:Si:O films deposited from HMDSO. Similarly, the values reported here are consistent with those of 1.55 reported by Amri et al. ${ }^{[24]}$ for films deposited from HMDSO and nitrogen at low power $(20 \mathrm{~W})$.

Tauc plots of the transmission spectra of the films, shown in Figure 9, allow the determination of the optical gap. The optical gap, shown as a function of $\mathrm{R}_{\text {ox }}$ in Figure 10, falls from $\sim 3.3$ to $\sim 2.3 \mathrm{eV}$ as $\mathrm{R}_{\mathrm{ox}}$ is increased. This interval overlaps with that of 1.87 and $2.7 \mathrm{eV}$ reported by Swatowska ${ }^{[8]}$ for a-C:H:Si:N films deposited from $\mathrm{CH}_{4}, \mathrm{SiH}_{4}$ e $\mathrm{NH}_{3}$. Greater nitrogen or carbon contents tend to increase the gap $^{[8]}$. Thus, the decline in $[\mathrm{C}]$ and $[\mathrm{N}]$ with increasing $\mathrm{R}_{\mathrm{ox}}$ may account, at least in part, for the observed fall in the gap. The decline also depends, however, on the densities and types of dangling, single and multiple bonds. The (unknown) hydrogen content probably accompanies the fall in [C]. Thus, the density, for example, of Si-O probably increases while that of $\mathrm{Si}-\mathrm{C}$ decreases. As bond lengths of $\mathrm{Si}-\mathrm{O}$ and $\mathrm{Si}-\mathrm{C}$ are about $163 \mathrm{pm}^{[41]}$ and $185 \mathrm{pm}^{[42]}$, respectively, such

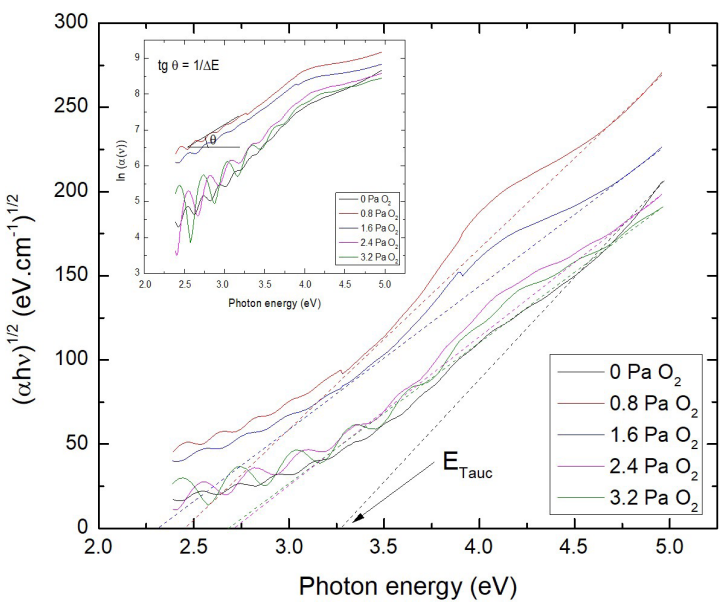

Figure 9. Tauc plots for films deposited at different $R_{0}$. Inset shows the variation of $\ln (\alpha(v))$ vs. the photon energy.

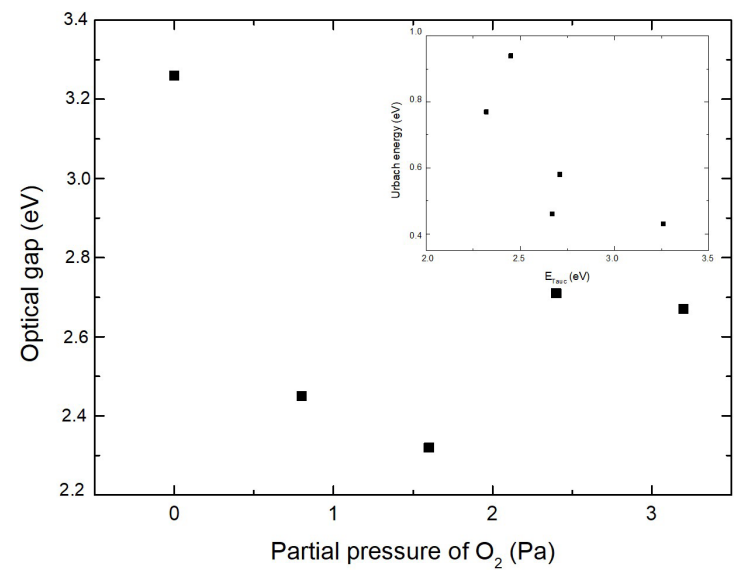

Figure 10. Optical gap of the deposited material as a function of $\mathrm{R}_{\mathrm{ox}}$. Inset shows the Urbach energy as a function of the optical gap. 
changes are expected to modify the optical transmittance and hence the gap.

A fall in the band gap of a-C:H:Si:O films at greater applied powers has been attributed to a greater density of dangling bonds, which are responsible for the formation of localized defects and hence of localized states in the band structure ${ }^{[43]}$. The reduction in the gap with increasing $\mathrm{R}_{\mathrm{ox}}$ is also consistent with the finding that greater $\mathrm{Si}-\mathrm{O}-\mathrm{Si}$ and $\mathrm{Si}-\mathrm{O}-\mathrm{C}$ concentrations in HMDSO plasma films are associated with lower gaps ${ }^{[19]}$.

The inset of Figure 9 shows plots of $\ln (\alpha) \vee$ E, for each film, from which Urbach energy, $\mathrm{E}_{\mathrm{U}}$, was calculated. The resulting $\mathrm{E}_{\mathrm{U}}$ values are shown as a function of the optical gap in Figure 10 (inset). A linear fall is observed, which is consistent with the behavior of other amorphous materials ${ }^{[44]}$. Greater values of $\mathrm{E}_{\mathrm{U}}$ (found at higher $\mathrm{R}_{\mathrm{ox}}$ ) are associated with disordering and defect states and thus with a reduction in the optical gap.

\section{Conclusions}

Smooth, hydrophobic a-C:H:Si:O:N thin films may be produced from cold plasmas fed mixtures of HMDSO-O $-\mathrm{N}_{2}$. The films have a complex structure, containing a network with Si-O-Si and C-C chains, similar to that reported by Hilbert et al. ${ }^{[45]}$ but with greater $\mathrm{Si}$ and $\mathrm{O}$ contents. The oxygen content generally rises, and the carbon content falls with increasing $\mathrm{R}_{\mathrm{ox}}$. Silicon contents are around 20 at.\% and nitrogen contents a few at. $\%$. At low $\mathrm{R}_{\mathrm{ox}}$ there are relatively high concentrations of $\mathrm{Si}-\mathrm{CH}_{3}$ groups, which accounts, at least in part, for the hydrophobicity of these films. As $\mathrm{R}_{\mathrm{ox}}$ increases, the incorporation of oxygen and complex structural changes, cause a decrease in the optical gap. Lower Urbach energies are associated with greater optical gaps.

Owing to the combination of hydrophobicity, smoothness, good adhesion to diverse substrates, and high optical transparency, films grown at low $\mathrm{R}_{\mathrm{ox}}$ may find application as transparent barrier coatings. Similar films have been investigated as interlayers for $\mathrm{SiO}_{\mathrm{x}}$ diffusion barrier coatings on polypropylene, but in this case plasma-polymerized HMDSO offered the advantage of greater deposition rates [22]. Films deposited from $\mathrm{HMDSO}-\mathrm{O}_{2}$-Ar mixtures may find application as multilayered organosilicon/silica films for the protection of metal surfaces ${ }^{[20]}$. Although there is a report of plasma-deposited nanocomposite hydrogenated silicon oxycarbonitride films obtained from tetramethlydisilazane$\mathrm{O}_{2}-\mathrm{N}_{2}$ mixtures $^{[23]}$, characterizations beyond chemical composition and structure are required to suggest possible applications of this material. The mechanical properties of our films, such as hardness, Young's modulus and stiffness, are also relevant to possible applications, but require separate study.

\section{Acknowledgements}

The authors thank Fundação de Amparo à Pesquisa do Estado de São Paulo (2017/15853-0) and Conselho Nacional de Desenvolvimento Científico e Tecnológico for financial support. This study was also financed in part by Coordenação de Aperfeiçoamento de Pessoal de Nível
Superior - Brasil, CAPES - Finance code 001. We thank Prof. José H. Dias da Silva for helpful discussion of the optical data and Jamille Altheman for technical assistance with the SEM/EDS measurements.

\section{References}

1. Gerstenberg, K. W., \& Beyer, W. (1987). Gas evolution studies for structural characterization of hexamethyldisilazane-based a-Si:C:N:H films. Journal of Applied Physics, 62(5), 17821787. http://dx.doi.org/10.1063/1.339556.

2. Levy, R. A., Grow, J. M., Yu, Y., \& Shih, K. T. (1995). Plasma enhanced chemical vapor deposition of Si-N-C-H films from environmentally benign organosilanes. Materials Letters, 24(13), 47-52. http://dx.doi.org/10.1016/0167-577X(95)00069-0.

3. Shimizu, T., Ishii, T., Kumeda, M., Matsuda, A. (1998). Structural and conductivity change caused by $\mathrm{N}, \mathrm{O}$ and $\mathrm{C}$ incorporation in a-Si:H. Journal of Non-crystalline Solids, 227-230(Pt 1), 403-406. http://dx.doi.org/10.1016/S0022-3093(98)00083-0.

4. Levy, R. A., Chen, L., Grow, J. M., \& Yu, Y. (2002). A comparative study of plasma enhanced chemically vapor deposited $\mathrm{SiOH}$ and $\mathrm{SiNCH}$ films using the environmentally benign precursor diethylsilane. Materials Letters, 54(2-3), 102-107. http://dx.doi.org/10.1016/S0167-577X(01)00545-6.

5. Vetter, M., Martin, I., Orpella, A., Puigdollers, J., Voz, C., \& Alcubilla, R. (2004). IR-study of a-SiCx: H and a-SiCxNy: H films for c-Si surface passivation. Thin Solid Films, 451-451, 340-344. http://dx.doi.org/10.1016/j.tsf.2003.10.125.

6. Tóth, A., Mohai, M., Ujvári, T., \& Bertóti, I. (2005). Surface and nanomechanical properties of Si:C:H films prepared by RF plasma beam CVD. Diamond and Related Materials, 14(3-7), 954-958. http://dx.doi.org/10.1016/j.diamond.2005.01.017.

7. Probst, D., Hoche, H., Zhou, Y., Hauser, R., Stelzner, T., Scheerer, H., Broszeit, E., Berger, C., Riedel, R., Stafast, H., \& Koke, E. (2005). Development of PE-CVD Si/C/N:H films for tribological and corrosive complex-load conditions. Surface and Coatings Technology, 200(1-4), 355-359. http:// dx.doi.org/10.1016/j.surfcoat.2005.02.111.

8. Swatowska, B., Kluska, S., Jurzecka-Szymacha, M., Stapinski, T., \& Tkacz-Smiech, K. (2016). The chemical composition and band gap of amorphous Si:C:N:H layers. Applied Surface Science, 371, 91-95. http://dx.doi.org/10.1016/j.apsusc.2016.02.198.

9. Tamulevičienė, A., Kopustinskas, V., Niaura, G., Meškinis, Š., \& Tamulevičius, S. (2015). Multiwavelength Raman analysis of $\mathrm{SiO}_{\mathrm{x}}$ and $\mathrm{N}$ containing amorphous diamond like carbon films. Thin Solid Films, 581, 86-91. http://dx.doi.org/10.1016/j. tsf.2014.11.042.

10. Nagasawa, H., Minamizawa, T., Kanezashi, M., Yoshioka, T., \& Tsuru, T. (2015). Microporous organosilica membranes for gas separation prepared via PECVD using different $\mathrm{O} / \mathrm{Si}$ ratio precursors. Journal of Membrane Science, 489, 11-19. http:// dx.doi.org/10.1016/j.memsci.2015.04.011.

11. Blanchard, N. E., Hanselmann, B., Drosten, J., Heuberger, M., \& Hegemann, D. (2015). Densification and Hydration of HMDSO Plasma Polymers. Plasma Processes and Polymers, 12(1), 32-41. http://dx.doi.org/10.1002/ppap.201400118.

12. Turri, R. G., Santos, R. M., Rangel, E. C., da Cruz, N. C., Bortoleto, J. R. R., Dias da Silva, J. H., Antonio, C. A., \& Durrant, S. F. (2013). Optical, mechanical and surface properties of amorphous carbonaceous thin films obtained by plasma enhanced chemical vapor deposition and plasma immersion ion implantation and deposition. Applied Surface Science, 280, 474-481. http://dx.doi.org/10.1016/j.apsusc.2013.05.013.

13. Bewilogua, K., Bialuch, I., Ruske, H., \& Weigel, K. (2011). Preparation of a-C:H/a-C:H:Si:O and a-C:H/a-C:H:Si multilayer 
coatings by PACVD. Surface and Coatings Technology, 206(4), 623-629. http://dx.doi.org/10.1016/j.surfcoat.2011.02.020.

14. Gelamo, R. V., Landers, R., Rouxinol, F. P. M., Trasferetti, B. C., Bica de Moraes, M. A., Davanzo, C. U., \& Durrant, S. F. (2007). XPS Investigation of plasma-deposited polysiloxane films irradiated with helium ions. Plasma Processes and Polymers, 4(4), 482-488. http://dx.doi.org/10.1002/ppap.200600100.

15. Veres, M., Koós, M., Tóth, S., Füle, M., Pócsik, I., Tóth, A., Mohai, M., \& Bertóti, I. (2005). Characterisation of aC:H and oxygen-containing Si:C:H films by Raman spectroscopy and XPS. Diamond and Related Materials, 14(3-7), 1051-1056. http://dx.doi.org/10.1016/j.diamond.2005.01.020.

16. Theirich, D., Soll, C., Leu, F., \& Engemann, J. (2003). Intermediate gas phase precursors during plasma CVD of HMDSO. Vacuum, 71(3), 349-359. http://dx.doi.org/10.1016/ S0042-207X(02)00763-7.

17. Barranco, A., Cotrino, J., Yubero, F., Espinós, J. P., Benítez, J., Clerc, C., \& González-Elipe, A. R. (2001). Synthesis of $\mathrm{SiO}_{2}$ and $\mathrm{SiO}_{\mathrm{x}} \mathrm{C}_{\mathrm{y}} \mathrm{H}_{\mathrm{z}}$ thin films by microwave plasma CVD. Thin Solid Films, 401(1-2), 150-158. http://dx.doi.org/10.1016/ S0040-6090(01)01632-7.

18. Schwarz, J., Schmidt, M., \& Ohl, A. (1998). Synthesis of plasma-polymerized hexamethyldisiloxane (HMDSO) films by microwave discharge. Surface and Coatings Technology, 98(1-3), 859-864. http://dx.doi.org/10.1016/S0257-8972(97)00319-8.

19. Mota, R. P., Galvão, D., Durrant, S. F., De Moraes, M. A. B., de Oliveira Dantas, S., \& Cantão, M. (1995). HMDSO plasma polymerization and thin film optical properties. Thin Solid Films, 270(1-2), 109-113. http://dx.doi.org/10.1016/00406090(95)06938-0.

20. Santos, N. M., Gonçalves, T. M., de Amorim, J., Freire, C. M. A., Bortoleto, J. R. R., Durrant, S. F., Ribeiro, R. P., Cruz, N. C., \& Rangel, E. C. (2017). Effect of the plasma excitation power on the properties of $\mathrm{SiO}_{\mathrm{x}} \mathrm{C}_{\mathrm{y}} \mathrm{H}_{\mathrm{z}}$ films deposited on AISI 304 steel. Surface and Coatings Technology, 311, 127-137. http://dx.doi.org/10.1016/j.surfcoat.2016.12.113.

21. Willich, P., \& Obertop, D. (1989). Quantitative electron-probe microanalysis of light elements: Determination of a-Si:C:N:O:H insulating films. Mikrochimica Acta, 98(4), 233-241. http:/ dx.doi.org/10.1007/BF01244599.

22. Körner, L., Sonnenfeld, A., Heuberger, R., Waller, J. H., Leterrier, Y., Månson, J A E., \& Rudolf von Rohr, P. (2010). Oxygen permeation, mechanical and structural properties of multilayer diffusion barrier coatings on polypropylene. Journal of Physics. D, Applied Physics, 43(11), 115301. http://dx.doi. org/10.1088/0022-3727/43/11/115301.

23. Fainer, N. I., Plekhanov, A. G., Golubenko, A. N., Rumyantsev, Y. M., Maksimovskii, E. A., \& Shayapov, V. R. (2017). Structure and elemental composition of transparent nanocomposite silicon oxycarbonitride films. Journal of Structural Chemistry, 58(1), 119-125. http://dx.doi.org/10.1134/S0022476617010188.

24. Amri, R., Sahel, S., Gamra, D., Lejeune, M., Clin, M., Zellama, K., \& Bouchriha, H. (2017). Photonic band gap and defect mode of one-dimensional photonic crystal coated from a mixture of (HMDSO, $\mathrm{N}_{2}$ ) layers deposited by PECVD. Superlattices and Microstructures, 104, 298-307. http://dx.doi.org/10.1016/j. spmi.2017.02.041.

25. Martin, I., Vetter, M., Orpella, A., Voz, C., Puigdollers, J., \& Alcubilla, R. (2002). Surface passivation of n-type crystalline Si by plasma-enhanced-chemical-vapor-deposited amorphous $\mathrm{SiC}_{\mathrm{x}}: \mathrm{H}$ and amorphous $\mathrm{SiC}_{\mathrm{x}} \mathrm{N}_{\mathrm{y}}: \mathrm{H}$ films. Applied Physics Letters, 81(23), 4461-4463. http://dx.doi.org/10.1063/1.1527230.

26. Gosar, Ž., Kovač, J., Đonlagić, D., Pevec, S., Primc, G., Junkar, I., Vesel, A., \& Zaplotnik, R. (2020). PECVD of hexamethyldisiloxane coatings using extremely asymmetric capacitative RF discharge. Materials (Basel), 13(9), 2147. http://dx.doi.org/10.3390/ma13092147. PMid:32384729.

27. Aumaille, K., Vallée, C., Granier, A., Goullet, A., Gaboriau, F., \& Turban, G. (2000). A comparative study of oxygen/ organosilicon plasmas and thin $\mathrm{SiO}_{\mathrm{x}} \mathrm{C}_{\mathrm{y}} \mathrm{H}_{\mathrm{z}}$ films deposited in a helicon reactor. Thin Solid Films, 359(2), 188-196. http:// dx.doi.org/10.1016/S0040-6090(99)00883-4.

28. Ricci, M., Dorier, J.-L., Hollenstein, C., \& Fayet, P. (2011). Influence of argon and nitrogen admisture in $\mathrm{HMDSO} / \mathrm{O}_{2}$ plasmas onto powder formation. Plasma Processes and Polymers, 8(2), 108-117. http://dx.doi.org/10.1002/ppap.201000052.

29. Maurau, R., Boscher, N. D., Guillot, J., \& Choquet, P. (2011). Nitrogen introduction in pp-HMDSO thin films deposited by atmospheric pressure dielectric barrier discharge: an xps study. Plasma Processes and Polymers, 9(3), 316-323. http://dx.doi. org/10.1002/ppap.201100144.

30. Degarmo, E. P., Black, J. T., \& Kosher, R. A. (2003). Materials and processes in manufacturing. New York: John Wiley \& Sons, Inc.

31. Cisneros, J. I., Rego, G. B., Tomyiama, M., Bilac, S., Gonçalves, J. M., Rodriguez, A. E., \& Argüello, Z. P. (1983). A method for the determination of the complex refractive index of non- metallic thin films using photometric measurements at normal incidence. Thin Solid Films, 100(2), 155-167. http:// dx.doi.org/10.1016/0040-6090(83)90471-6.

32. Tauc, J. (1972). Optical properties of solids (pp. 277). Amsterdam: North-Holland Publishing Company.

33. Balu, B., Breedveld, V., \& Hess, D. W. (2008). Fabrication of roll-off and sticky superhydrophobic cellulose surfaces via plasma processing. Langmuir, 24(9), 4785-4790. http://dx.doi. org/10.1021/la703766c. PMid:18315020.

34. Steinbruchel, C., Curtis, B. J., Lehmann, H. W., \& Widmer, R. (1986). Diagnostics of low-pressure oxygen RF plasmas and the mechanism for polymer etching: A comparison of reactive sputter etching and magnetron sputter etching. IEEE Transactions on Plasma Science, 14(2), 137-144. http://dx.doi. org/10.1109/TPS.1986.4316516.

35. Da Cruz, N. C., Durrant, S. F., \& De Moraes, M. A. B. (1998). Thin film deposition from plasmas of tetramethylsilane-helium-argon mixtures with oxygen and with nitrogen. Journal of Polymer Science. Part B, Polymer Physics, 36(11), 1873-1879. http:// dx.doi.org/10.1002/(SICI)1099-0488(199808)36:11<1873::AIDPOLB8>3.0.CO;2-R.

36. Li, J., Yuan, Q., Chang, X., Wang, Y., Yin, G., \& Dong, C. (2017). Deposition of organosilicone thin film from hexamethyldisiloxane (HMDSO) with $50 \mathrm{kHz} / 33 \mathrm{MHz}$ dual-frequency atmosphericpressure plasma jet. Plasma Science \& Technology, 19(4), 045505. http://dx.doi.org/10.1088/2058-6272/aa57e4.

37. Morosoff, N., Crist, B., Bumgarner, M., Hsu, T., \& Yasuda, H. (1976). Free radicals resulting from plasma polymerization and plasma treatment. Journal of Macromolecular Science: Part A - Chemistry, 10(3), 451-471. http://dx.doi. org/10.1080/00222337608061192.

38. Yasuda, H., Bumgarner, M. O., Marsh, H. C., \& Morosoff, N. (1976). Plasma polymerization of some organic compounds and properties of the polymers. Journal of Polymer Science: Polymer Chemistry Edition, 14(1), 195-224. http://dx.doi. org/10.1002/pol.1976.170140118.

39. Lanford, W. A., \& Rand, M. J. (1978). The hydrogen content of plasma-deposited silicon nitride. Journal of Applied Physics, 49(4), 2473-2477. http://dx.doi.org/10.1063/1.325095.

40. Ghiner, A. V., \& Surdutovich, G. I. (1996). Clausius-Mossotti and Lorentz-Lorenz Formulas: What is the Difference? In Eberly J. H., Mandel L., \& Wolf, E. (Eds.), Coherence and Quantum Optics VII (pp. 683-684). Boston: Springer. http:// dx.doi.org/10.1007/978-1-4757-9742-8_212. 
41. Capaz, R. B., Assali, L. V. C., Kimerling, L. C., Cho, K., \& Joannopoulos, J. D. (1999). "Ab Initio" studies of hydrogenenhanced oxygen diffusion in silicon. Brazilian Journal of Physics, 29(4), 611-615. http://dx.doi.org/10.1590/S010397331999000400002 .

42. Firme, C. L. (2020). Introductory chemistry and hydrocarbons: a physical chemistry approach. USA:CRC Press. http://dx.doi. org/10.1201/9781351205795.

43. Saloum, S., \& Naddaf, M. (2008). Optical constants of silicone-like $\left(\mathrm{Si}_{\mathrm{O}}: \mathrm{O}_{\mathrm{y}}: \mathrm{H}_{\mathrm{z}}\right)$ thin films deposited on quartz using hexamethyldisiloxane in a remote rf hollow cathode discharge plasma. Vacuum, 82(1), 50-55. http://dx.doi.org/10.1016/j. vacuum.2007.03.007.
44. Grenadyorov, A. S., Oskomov, K. V., \& Solovyev, A. A. (2018). Effect of deposition conditions on optical properties of a-C:H:SiOx films prepared by plasma-assisted chemical vapor deposition method. Optik (Stuttgart), 172, 107-116. http://dx.doi.org/10.1016/j.ijleo.2018.07.024.

45. Hilbert, J., Mangolini, F., McClimon, J. B., Lukes, J. R., \& Carpick, R. W. (2018). Si doping enhances the thermal stability of diamond-like carbon through reductions in carbon-carbon bond length disorder. Carbon, 131, 72-78. http://dx.doi. org/10.1016/j.carbon.2018.01.081.

Received: June 01, 2021 Revised: Oct. 06, 2021 Accepted: Nov. 29, 2021 